\title{
Desulfurization of Thioketals into Methylene and Methyl Derivatives: Nickel or not Nickel?
}

\author{
Guangkuan Zhao, ${ }^{[\mathrm{a}]}$ Ling-Zhi Yuan, ${ }^{[\mathrm{a}]}$ Mouad Alami, ${ }^{[\mathrm{a}]}$ and Olivier Provot ${ }^{\mathrm{[a]}}$
}

\begin{abstract}
In this review, the desulfurization of thioacetals and thioketals leading to methyl and methylene derivatives is summarized through metal and metal-free methodologies. In the section concerning the use of metals for desulfurization reactions, we will be successively presenting and discussing all methods requiring $\mathrm{Ni}$ and $\mathrm{Ni}$ derivatives as reducing agents and other examples in which metals were used to generate solvating
\end{abstract}

1. Introduction

2. Desulfurization of thioacetals using metals

$2.1 \quad$ Raney-Ni

$2.2 \quad$ Other Nickel derivatives

2.2.1. $\mathrm{NiCRAs}$ from $\mathrm{Ni}(\mathrm{OAc})_{2}, \mathrm{NaH}$ and $t$-amylalcohol

2.2.2. " $\mathrm{Ni}_{2} \mathrm{~B}$ " from $\mathrm{NiCl}_{2}$ and $\mathrm{NaBH}_{4}$

2.2.3. $\mathrm{NiBr}_{2} \cdot \mathrm{DME}, \mathrm{PPh}_{3}$ and $\mathrm{LiAlH}_{4}$

2.2.4. Nickelocene-LiAlH ${ }_{4}$ hydride

2.3. Other metals

2.3.1. $\mathrm{Na}$ and $\mathrm{Li}$ in liquid $\mathrm{NH}_{3}$

2.3.2. $\mathrm{Li}$ in $\mathrm{EtNH}_{2}$

2.3.3. $\mathrm{LiAlH}_{4}$ associated with $\mathrm{CuCl}_{2} / \mathrm{ZnCl}_{2}$ or withTiCl 4

2.3.4. Miscellaneous metal processes using $\mathrm{Mo}(\mathrm{CO})_{6}$ and $\mathrm{Sml}_{2}$

3. Other desulfurizing reagents

3.1. Metal hydrides

3.1.1. $\mathrm{Bu}_{3} \mathrm{SnH}$ with $\mathrm{AIBN}$

3.1.2. $\quad B\left(C_{6} \mathrm{~F}_{5}\right)_{3}$ catalyzed desulfurization of thioketals in the presence of $\mathrm{Et}_{3} \mathrm{SiH}$

3.2. Metal-free desulfurizations

3.2.1. Hydrated hydrazine

3.2.2. $\mathrm{P}_{2} \mathrm{I}_{4}$ in $\mathrm{CH}_{2} \mathrm{Cl}_{2}$

3.2.3. Photoreduction of dithianes and dithiolanes with tBuOK in DMSO

3.2.4. EtSNa in $\mathrm{MeOH}$

4. Conclusion

[a] BioCIS, Univ. Paris-Sud, CNRS, Université Paris-Saclay, 92290 Châtenay-Malabry, France.

E-mail: olivier.provot@u-psud.fr

Supporting information for this article is given via a link at the end of the document.((Please delete this text if not appropriate)) electrons as reducing species. The following section will concern the use of other desulfurizing agents as metal-hydrides $\left(\mathrm{Bu}_{3} \mathrm{SnH}\right.$, $\mathrm{Et}_{3} \mathrm{SiH}$ ) and metal-free desulfurization reactions of thioketals. The functional group tolerance of the presented methods with functionalized and sensitive substrates will be discussed.

\section{Introduction}

Desulfurization of dithioacetal, thiolane and dithiane function into a methyl or methylene group is an important chemical transformation, which can be applied almost under neutral conditions. The desulfurizing process of thioacetal derivatives is often preferable to Clemmensen or Wolff-Kischner reductions of carbonyl compounds, particularly in the case of acidic or basic sensitive substrates. The Ni-promoted desulfurization transformation $^{[1 \text { a] }}$ of thioketals, known as "Mozingo reaction", was firstly described in 1944 by Wolfrom and Karabinos, which used Raney-nickel to reduce a thioacetal function into a methylene group (Scheme 1). ${ }^{[\mathrm{b}]}$

$$
\underset{R^{-}}{\text {EtS }} X_{\mathrm{R}^{1}}^{\text {SEt }} \underset{\text { EtOH reflux }}{\stackrel{\text { Raney Ni }}{\longrightarrow}} \mathrm{R}-\mathrm{CH}_{2}-\mathrm{R}^{1}
$$

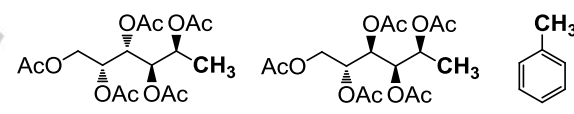

$$
66 \%
$$

$60 \%$

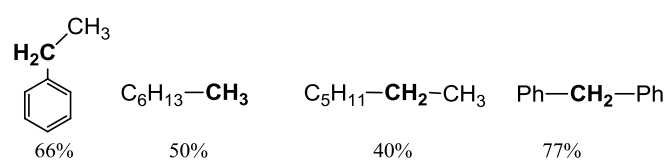

Scheme 1. First thioacetals hydrogenolysis by Raney-Ni.

In the present review, a compilation of the existing methods reported to achieve this transformation from various thioacetals of aldehyde and ketone derivatives will be highlighted. In the section 2 of this review, we will also present in a non-exhaustive manner, some selected examples using metals as reducing agents in which Raney$\mathrm{Ni}^{[2]}$ and Ni-derivatives predominate beside other Raney-Ni of special activity (W1 to W8). The use of solvated electrons generated by other metals to perform these desulfurization reactions will be discussed afterwards. Section 3 will deal with desulfurization reactions performed in the presence of metal hydrides and the use of non-metallic processes will be explored. 


\section{Desulfurization of thioacetals using metals}

\subsection{Raney-Ni}

From all the methods of thioacetals desulfurization, the use of Raney-Ni is by far the most used method since the pioneer work of Wolfrom and Karabinos. ${ }^{[1 b]}$ This is probably due to the easy access to this catalyst and to the fact that Raney-Ni tolerates a large number of functional groups. ${ }^{[2]}$ The preparation of Raney- $\mathrm{Ni}^{[3]}$ has been largely reported by Raney ${ }^{[4]}$ and others, ${ }^{[5]}$ who mixed finely powdered NickelAluminum alloy in a hot alkali solution. One can note that during this process, a large quantity of molecular hydrogen $\left(\mathrm{H}_{2}\right)$ was produced with considerable amounts of $\mathrm{H}_{2}$ remained on the metal. For this reason, a large number of desulfurization reactions were achieved without the need of an external source of $\mathrm{H}_{2}$. However, side-reactions such as debenzylation, ${ }^{[6]}$ carbon-carbon double bond reduction, ${ }^{[7]}$ hydrogenolysis of a carbon-halogen bonds ${ }^{[8]}$ and deoxygenation of an epoxide ${ }^{[9]}$ sometimes occurred, greatly lowering the yield of the process. In Scheme 2, we have selected some recent representative examples using Raney$\mathrm{Ni}$ to desulfurize poly-functionalized molecules in total or complex syntheses. ${ }^{[9,10]}$

It was noted that, alcohols like $\mathrm{MeOH}$ and $\mathrm{EtOH}$ are the solvents of choice in the great majority of these reducing transformations. A great functional group tolerance was observed in the selected examples requiring Raney-Ni among which heterocycles, ketones, quinones, alcohols, OTIPS, OBn,
NTs, esters, lactones and multiple bonds remained unchanged. It should be added that in some cases, the use of additional $\mathrm{H}_{2}$ source is needed (e.g., reduction of compounds 3, 5 and 11).

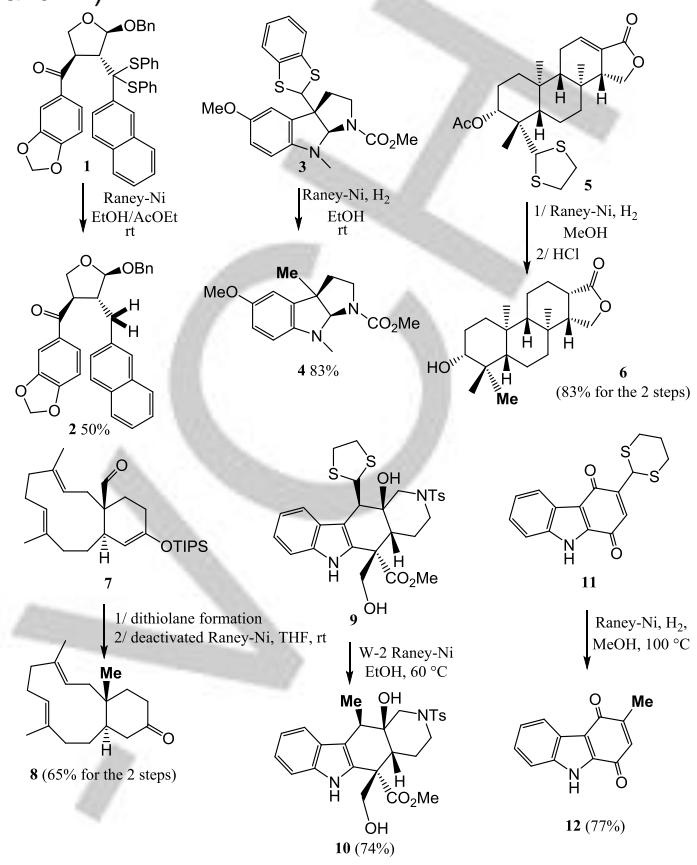

Scheme 2. Application of desulfurization reactions by Raney-Ni in total syntheses
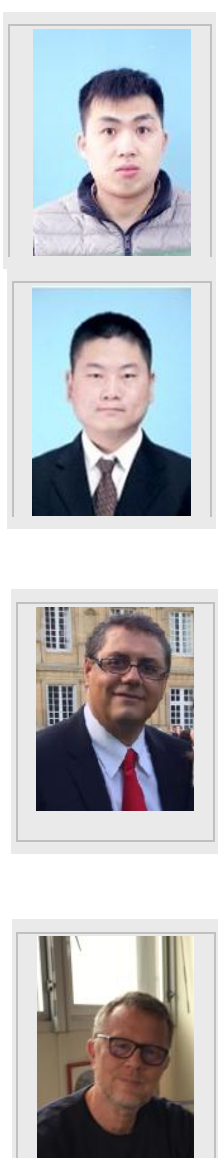

Guangkuan Zhao was born in 1988 in Shandong Province, China. He spent four years (2008-2012) in Ludong University pursuing bachelor degree of basic chemistry. After, he moved to Zhengzhou University where he obtained his master degree (organic chemistry, 2012-2015) under the supervision of Professor Dapeng Zou. He is currently a PhD student and works on chemical methodology and antitumor molecules with Dr. Olivier Provot in the Faculty of Pharmacy, University Paris-Saclay.

Dr. Ling-Zhi YUAN was born in 1987 in Huang-shi (Hubei Province, China) and granted with National Scholarship (2007-2008) during undergraduate period. After he received his master degree in 2013 with Prof. Jing-Yuan XU at Tianjin Medical University, he received his $\mathrm{PhD}$ in 2017 on selective metal-free deoxygenation of unsymmetrical 1,2-dicarbonyl compounds under the supervision of Dr. Olivier Provot in the Faculty of Pharmacy, University Paris-Saclay.

Dr. Mouad Alami, 58 years is a Research Director at the CNRS (Faculty of Pharmacy, BioCIS, France). He did his PhD at UPMC in Paris (1987) and after two years of post-doctoral position in collaboration with the Elf-Atochem company, he joined in 1989 the CNRS at the ENS-Paris (Dr. G. Linstrumelle). In 1993, he spent one year at the University of Santa-Barbara (Pr. B. H. Lipshutz). In 1999, he became CNRS Research Director at the Faculty of Pharmacy (University Paris-Saclay). His fields of specialization includes: (i) development of novel selective synthetic methodologies involving organometallic chemistry and (ii) synthesis of structurally challenging and biologically relevant products with antitumoral activity as vascular disrupting agents (VDAs) and their application in the context of antibody-drug conjugates.

Dr. Olivier Provot was born in 1963 in the beautiful city of Caen (Normandy, France) and received his PhD in total synthesis of ant venom alkaloids in the Lab of Pr. G. Lhommet in 1991 (UPMC, Paris VI). After a post-doctoral position in industry for two years and then for one year in the Lab of Medicinal Chemistry of Pr. R.Milcent (University Paris VII), he moved in the Lab of Pr. H. Moskowitz as assistant Professor in 1993 (University of Paris-Sud) and worked on the synthesis of natural peroxides having antimalarial activities. In 2003, he joined the group of Pr. J.-D. Brion and Dr. M. Alami (University Paris-Saclay) to develop novel organometallic methodologies to prepare novel anti-cancer drugs related to Combretastatin A-4. 


\subsection{Other Nickel derivatives}

Even if Raney-Ni are efficient reagents in desulfurization reactions and very often compatible with functional groups, some experiments failed to give the expected products. Otherwise, the desulfurization properties of Raney nickels were attributed to the large excess of $\mathrm{H}_{2}$ finely adsorbed on the catalyst's surface during its preparation, ${ }^{[5 a, 11]}$ which can be deleterious with sensitive functionalized molecules. Moreover, Raney-Ni is highly pyrophoric and difficult to handle and it is also difficult to exactly determine the amount of nickel used for these transformations. To overcome these difficulties, a variety of non-pyrophoric nickel-containing reducing agents (NiCRAs) were prepared and used for the desulfurization of thioacetals and thioketals.

\subsubsection{NiCRAs from $\mathrm{Ni}(\mathrm{OAc})_{2}, \mathrm{NaH}$ and $t$-amylalcohol}

In the 1980s, Caubère and co-workers developed easy to handle and to weigh nickel complexes from the reaction of $\mathrm{NaH}, t$-amylalcohol and $\mathrm{Ni}(\mathrm{OAc})_{2}$ with or without ligands. The NiCRAs (Ni-containing reducing agents) were able to reduce a wide variety of functions, ${ }^{[12]}$ and were also used as catalysts for coupling reactions. ${ }^{[13]}$ These NiCRAs complexes were also efficiently used to desulfurize a wide variety of sulfurcontaining substrates including thioacetals ${ }^{[14]}$ because these nickel reagents possessed a high single electron transfer (SET) ability. ${ }^{[15]}$ Some representative examples are depicted in Scheme 3.

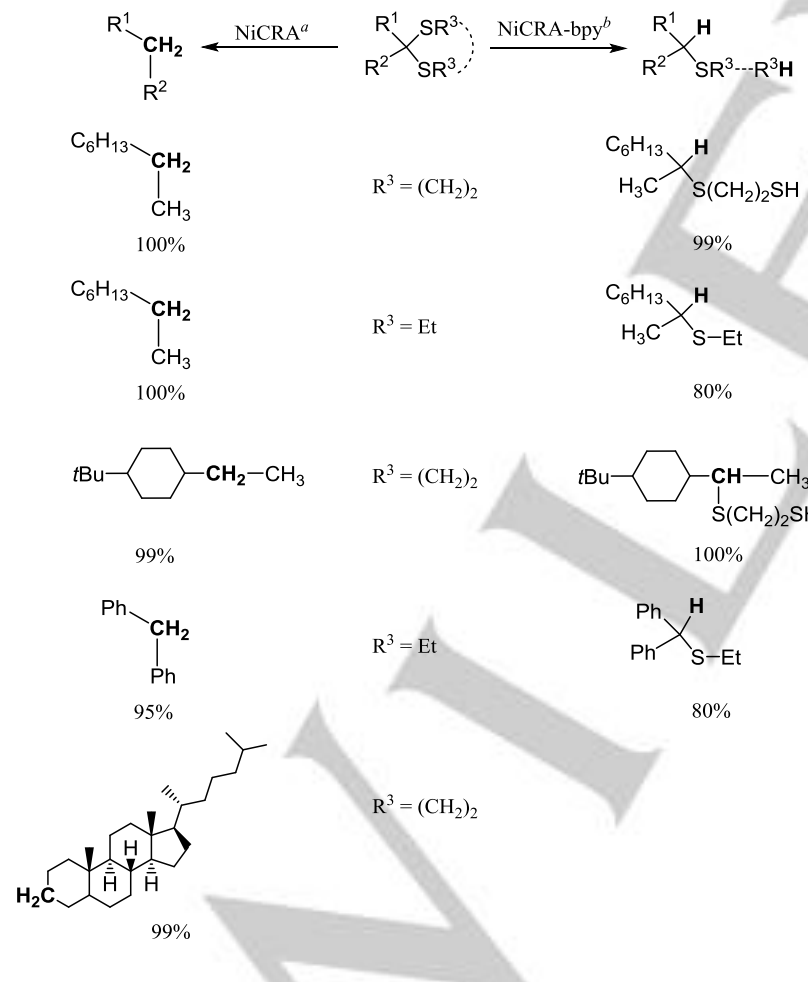

Scheme 3. Reagent and conditions: ${ }^{a} \mathrm{NiCRA}$ was prepared with $t \mathrm{AmOH}$ $(20 \mathrm{mmol})$ in THF, NaH $(70 \mathrm{mmol})$ and $\mathrm{Ni}(\mathrm{OAc})_{2}(10 \mathrm{mmol})$. Reaction performed on $1 \mathrm{mmol}$ scale with NiCRA in THF at $65^{\circ} \mathrm{C}$ with a ratio Ni/S $=$ 30. ${ }^{b} \mathrm{NiCRA}$-bpy was prepared with $t-\mathrm{AmOH}(20 \mathrm{mmol})$ in DME, NaH $(60$ $\mathrm{mmol}), \mathrm{Ni}(\mathrm{OAC})_{2}(10 \mathrm{mmol})$ and $2,2^{\prime}$-bipyridine $(20 \mathrm{mmol}) .{ }^{14}$
NiCRA, prepared from $\mathrm{Ni}(\mathrm{OAc})_{2}, \mathrm{NaH}$ and $t-\mathrm{AmOH}$ in THF totally desulfurized the thioacetals shown in Scheme 3 with excellent yields (GC). Caubère also demonstrated that a weaker reducing complex (e.g., NiCRA-bpy), ${ }^{[15]}$ prepared by adding 2,2'-bi-pyridine to NiCRA, was able to open only one of the two $\mathrm{C}$-S bonds by a half-desulfurization process, which was not easy to control with other Ni complexes. ${ }^{[14 a]}$ It should be noted that $t-\mathrm{AmOH}$ can be replaced by $\mathrm{N}$-methyl-3hydroxypiperidine to obtain the reduced compounds from thioacetals with no loss in yields. ${ }^{[14 c]}$ Moreover, in this study, the authors demonstrated that NiCRA totally desulfurized 3,3ethylene dithiocholestane $(99 \%)$ whereas, this reaction gave a mixture of compounds with $\mathrm{Ni}_{2} \mathrm{~B}$ (prepared from $\mathrm{Ni}$ (II) salts and $\mathrm{NaBH}_{4}$, see the next section). ${ }^{[16]}$ In our opinion, the main problem associated with NiCRAs is their use in large excess for desulfurization reactions (atom ratio $\mathrm{Ni} / \mathrm{S}=5$ to 30 ).

\subsection{2. " $\mathrm{Ni}_{2} \mathrm{~B}$ " from $\mathrm{NiCl}_{2}$ and $\mathrm{NaBH}_{4}$}

$\mathrm{Ni}_{2} \mathrm{~B}$ is a weak reducing agent prepared from the reduction of $\mathrm{NiCl}_{2}$ by $\mathrm{NaBH}_{4}$ to give an easy to handle black nonpyrophoric precipitate. However, $\mathrm{Ni}_{2} \mathrm{~B}$ can also be used directly in the reaction flask from $\mathrm{NiCl}_{2}$ and $\mathrm{NaBH}_{4}$ in the presence of the sulfur compounds without prior preparation. The advantages of $\mathrm{Ni}_{2} \mathrm{~B}$ compared to Raney-Ni are easy handling, the possible determination of the $\mathrm{Ni}$ amount used, and lower reactivity. Some representative examples are depicted in Scheme 4.

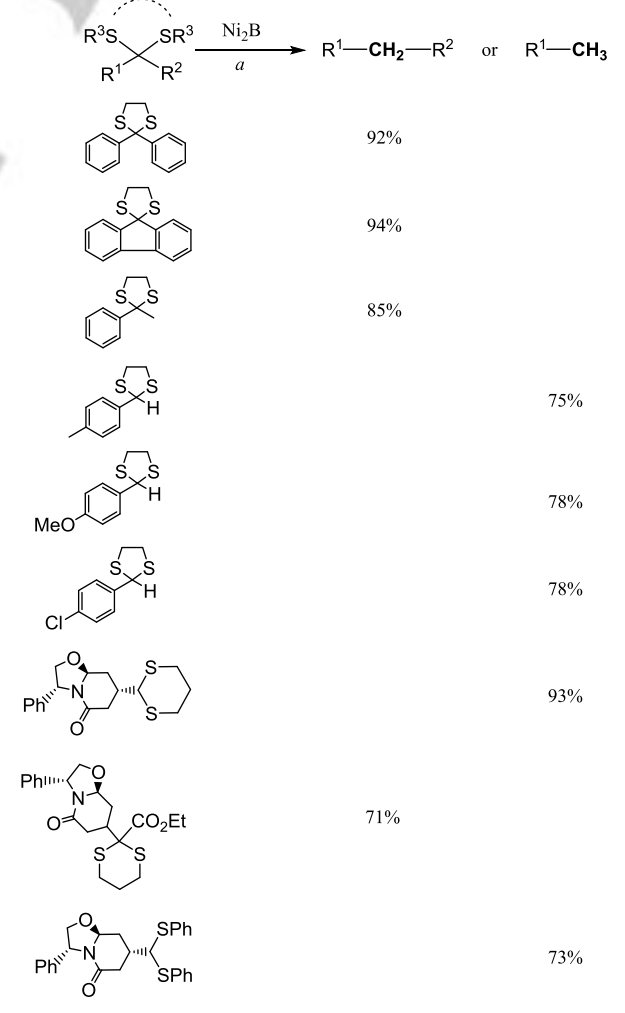

Scheme 4. Reagent and conditions: ${ }^{a}$ thioacetal ( 1 equiv), $\mathrm{NiCl}_{2}-6 \mathrm{H}_{2} \mathrm{O}$ (5 to 10 equiv), $\mathrm{NaBH}_{4}$ (10 to $30 \mathrm{mmol}$ ) in $\mathrm{MeOH}-\mathrm{THF}, 0^{\circ} \mathrm{C}$ to rt. 


1,2-Thiolanes, ${ }^{[17 a]}$ 1,3-dithianes ${ }^{[17 b]}$ and bis-
phenylsulfanes ${ }^{[17 b]}$ were rapidly desulfurized by the in situ prepared $\mathrm{Ni}_{2} \mathrm{~B}$. Reactions occurred at room temperature in few hours, using a very simple workup to provide methyl and methylene derivatives in good to excellent yields. As observed with NiCRAs, the quantities of $\mathrm{Ni}_{2} \mathrm{~B}$ are important (atom Ni/atom $\mathrm{S}$ from 5 to 10). Some functional groups (e.g., halogen, OMe, ester or lactam) were well tolerated under the reaction conditions. One can note that, due to the low reactivity of $\mathrm{Ni}_{2} \mathrm{~B}$, the total desulfurization of thioacetals can be complicated and two successive reduction steps with halfdesulfurized compounds as intermediates were needed. ${ }^{[18]}$

\subsection{3. $\mathrm{NiBr}_{2} \cdot \mathrm{DME}, \mathrm{PPh}_{3}$ and $\mathrm{LiAlH}_{4}$}

Luh and co-workers studied the reduction of sulfoxides and sulfones by nickel complexes and also found that the use of $\mathrm{NiBr}_{2} \cdot \mathrm{DME}, \mathrm{PPh}_{3}$ and $\mathrm{LiAlH}_{4}$ combination was able to totally desulfurize a dithioacetal and a bis-dithioacetal function. In the examples depicted in Scheme $5,{ }^{[19]}$ the nickel complex was prepared by mixing $\mathrm{NiBr}_{2}$. DME with 2 equiv of $\mathrm{PPh}_{3}$ and 2 equiv of $\mathrm{LiAlH}_{4}$ in THF at room temperature to give a dark solution in which was syringed thioacetals. Unfortunately, no comparison with Raney-Ni or NiCRAs was described for the desulfurization of fluorenonedithioacetal and bis-dithioacetal. It would be also interesting to consider if this Ni-complex is compatible with sensitive functional groups.

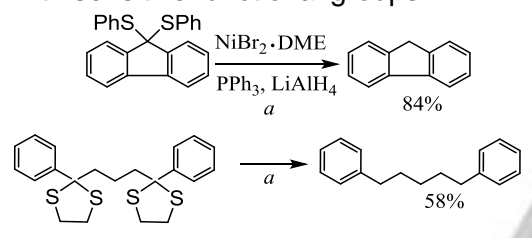

Scheme 5. Desulfurization of thioacetals by $\mathrm{NiBr}_{2} \cdot \mathrm{DME}, \mathrm{PPh}_{3}$ and $\mathrm{LiAlH}_{4}$. Reaction and conditions: ${ }^{a} \mathrm{NiBr}_{2}, \mathrm{PPh}_{3}$ (2 equiv) and $\mathrm{LiAlH}_{4}$ (2 equiv) in THF at $\mathrm{rt}$ were mixed with dithioacetal.

\subsubsection{Nickelocene-LiAlH hydride $^{[20]}$}

Luh also reported that nickelocene reacted with mercaptans to give the corresponding binuclear complexes ${ }^{[21]}$ in which the carbon-sulfur bond was activated and can be reduced by $\mathrm{LiAlH}_{4} \cdot{ }^{\left[{ }^{[2]}\right.}$ Keeping this idea in mind, Luh studied the reductive properties of a complex nickelocene-LiAlH ${ }_{4}$ for the desulfurization of thiols, sulfoxides, sulfones, and thioethers including three examples of thioacetals (Scheme 6). As it can be observed, by using this homogeneous organonickel reagent, isolated yields in reduced compounds were poor by comparison with other Ni-reducing reagents. It has been showed with other substrates that this nickel complex was compatible with several functional groups (halogen, $\mathrm{MeO}, \mathrm{CF}_{3}$, carbonyl, ester,...) but a $\mathrm{NO}_{2}$ function was unstable under the reaction conditions.

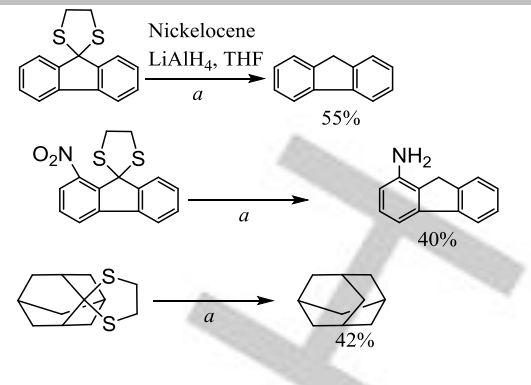

Scheme 6. Desulfurization of dithiolanes with nickelocene and $\mathrm{LiAlH}_{4}$ Reaction and conditions: ${ }^{2}$ Nickelocene ( 0.5 equiv) was mixed with $\mathrm{LiAlH}_{4}$ ( 0.5 equiv) and dithiolanes in THF at rt.

\subsection{Other metals}

\subsection{1. $\mathrm{Na}$ and $\mathrm{Li}$ in liquid $\mathrm{NH}_{3}$}

The first desulfurization of a 1,2-thiolane using solvated electrons generated from $\mathrm{Na}$ in liquid ammonia was published by Ireland and co-workers in 1958. ${ }^{[23]}$ The authors reported that the ethylene thioketal of cholest-4-en-3-one was efficiently reduced to give the expected cholest-4-ene (89\%) with no reduction of the internal double bond (Scheme 7).

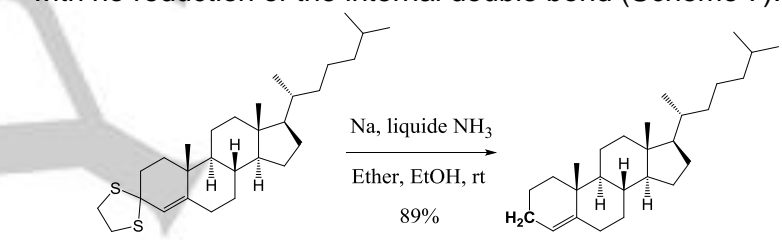

Scheme 7. First desulfurization of a thioketal using solvated electrons generated from $\mathrm{Na}$ in liquid ammonia.

This protocol was efficiently used few years later by Fochi $^{[24]}$ and Clive ${ }^{[25]}$ with 1,3-benzodithiol derivatives. The results of these studies are compacted in Scheme 8.

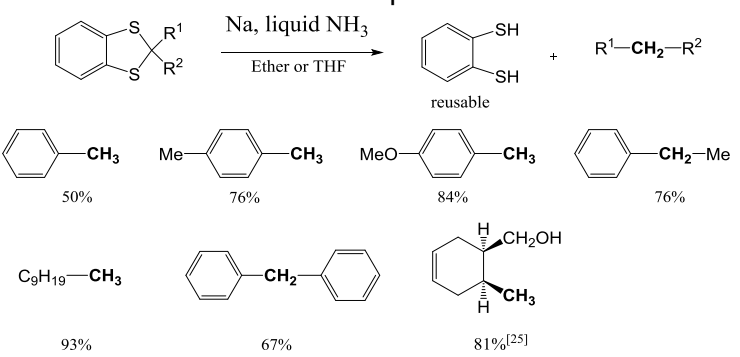

Scheme 8. Selection of desulfurization of 1,3-benzodithiolanes by solvated electrons generated from $\mathrm{Na}$ in liquid ammonia.

The authors indicated that, beside high yields, another advantage was to possibly recover a large amount of the starting benzene-1,2-dithiol. ${ }^{[24]}$ In liquid ammonia, solvated electrons can also be generated from $\mathrm{Li}$ as showed by Zeelen during the total synthesis of dl-19-Nor-4-pregnen-20-one (Scheme 9). ${ }^{[26]}$ 


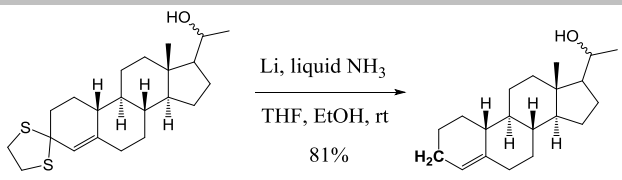

Scheme 9. Desulfurization of a thioketal by solvated electrons generated from $\mathrm{Li}$ in liquid ammonia.

Authors pointed out that a keto group on C-20 was not compatible with this desulfurizing process on the contrary to a secondary alcohol function, which was subsequently oxidized by chromic acid. ${ }^{[26]}$

\subsection{2. $\mathrm{Li}$ in $\mathrm{EtNH}_{2}$}

Crossley and Henbest reported that Li/liquid ammonia can be replaced by $\mathrm{Li} / \mathrm{EtNH} \mathrm{H}_{2}$ for the electron-mediated desulfurization of thioketals of perhydroanthracenes. ${ }^{[27 a]}$ This protocol produced the methylene compounds in good yields did not affect the stereochemistry of the bridge head positions. The desulfurization process was slow and not selective since double bonds present within the structures were also reduced (Scheme 10). Replacement of $\mathrm{Li}$ in $\mathrm{EtNH}_{2}$ at $-20^{\circ} \mathrm{C}$ by Raney$\mathrm{Ni}$ did not improve the selectivity and the yields of this process. This protocol was successfully transposed during the synthesis of Lasiol, an olfactory compound with no-reduction of the tri-substituted double bond. ${ }^{[27 b]}$

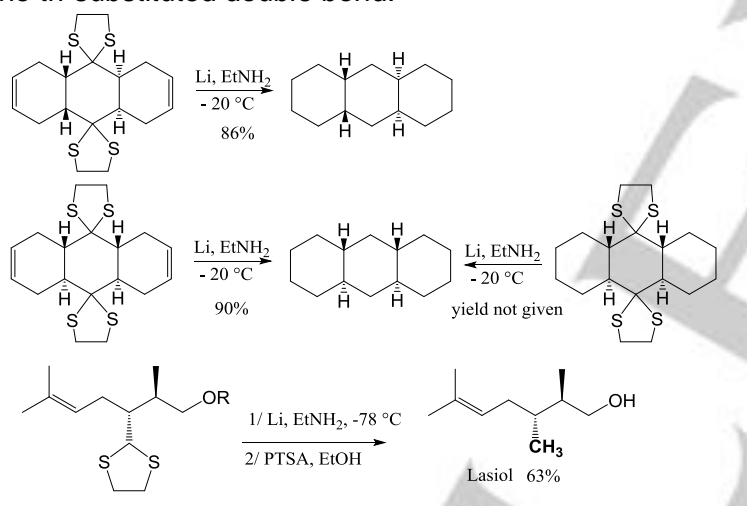

Scheme 10. Desulfurization of thioketals by solvated electrons generated from $\mathrm{Li}$ in $\mathrm{EtNH}_{2}$.

\subsection{3. $\mathrm{LiAlH}_{4}$ associated with $\mathrm{CuCl}_{2} / \mathrm{ZnCl}_{2}$ or withTiCl 4}

During his work concerning the reducing properties of $\mathrm{CuCl}_{2}$ with $\mathrm{LiAlH}_{4}$, Mukaiyama observed that the yield in diphenylmethane was doubled (84\%) when $\mathrm{ZnCl}_{2}$ was added to the reducing $\mathrm{LiAlH}_{4}-\mathrm{CuCl}_{2}$ combination ${ }^{[28 \mathrm{a}]}$ (Scheme 11). However, 4 equiv of $\mathrm{ZnCl}_{2}$ and $\mathrm{CuCl}_{2}$ together with 16 equiv of $\mathrm{LiAlH}_{4}$ were needed to achieve this transformation, which was not studied with functionalized substrates. Two years after, in 1973, Mukaiyama successfully replaced the couple $\mathrm{ZnCl}_{2} / \mathrm{CuCl}_{2}$ by $\mathrm{TiCl}_{4}$ in the presence of $\mathrm{LiAlH}_{4}$ to desulfurize thioketals. ${ }^{[28 \mathrm{~b}]}$ Best conditions were found by using 4 equiv of $\mathrm{LiAlH}_{4}$ with 2 equiv of $\mathrm{TiCl}_{4}$ to provide the expected methylene products in yields ranging from 80 to $97 \%$.

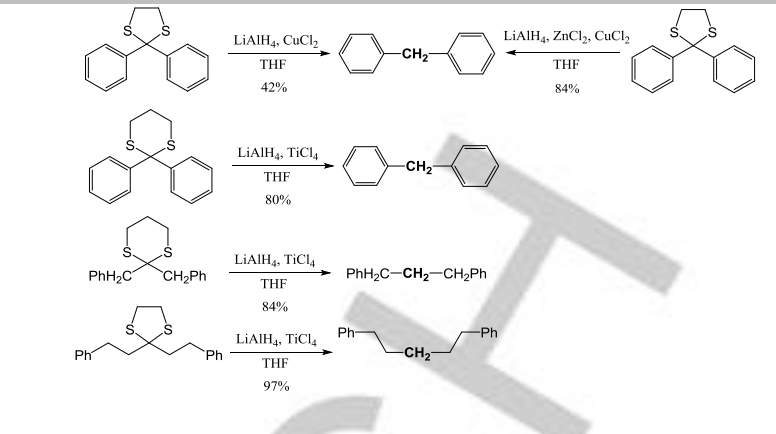

Scheme 11. $\mathrm{LiAlH}_{4}$ associated to $\mathrm{CuCl}_{2} / \mathrm{ZnCl}_{2}$ or $\mathrm{TiCl}_{4}$.

Unfortunately, these experimental conditions were not reported with functionalized dithioketals in which reducible functional groups would not be probably tolerated.

\subsubsection{Miscellaneous metal processes using $\mathrm{Mo}(\mathrm{CO})_{6}$ and} $\mathrm{Sml}_{2}$

Alper and Blais reported in 1980 that $\mathrm{Mo}(\mathrm{CO})_{6}$ adsorbed on siliga gel was able to reduce dibenzothiophene ${ }^{[29]}$ into biphenyl. Based on this observation, Luh studied the desulfurization of a series of compounds containing sulfur and only one example of a 1,2-thiolane reduction was reported ${ }^{[30]}$ (Scheme 12).
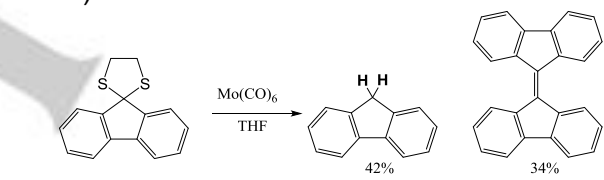

Scheme 12. Desulfurization of 9-fluorenone thioketal by $\mathrm{Mo}(\mathrm{CO})_{6}$. Reaction and conditions: $\mathrm{Mo}(\mathrm{CO})_{6}$ (1 equiv) was mixed with dibenzothiophene in THF at rt.

However, fluorene was obtained in a poor yield of $42 \%$ together with its dimer (34\%) which was formed from a molybdenium-carbene complex, making this process unattractive for desulfurization of thioketals.

To close this section dedicated to desulfurization reactions by metals, Hilmersson reported in 2003 that $\mathrm{Sml}_{2} / \mathrm{H}_{2} \mathrm{O} / n \mathrm{nuNH} \mathrm{H}_{2}$ was able to transform a dithioacetal into its methyl derivative ${ }^{[31]}$ through a single example depicted in Scheme 13.

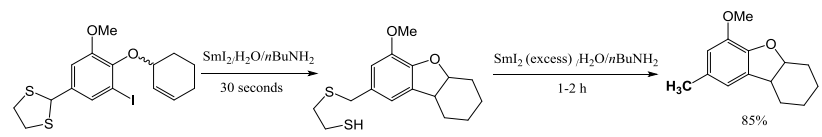

Scheme 13. Desulfurization of a dithioacetal by $\mathrm{Sml}_{2} / \mathrm{H}_{2} \mathrm{O} / n \mathrm{nuNH} \mathrm{H}_{2}$. Reaction and conditions: $\mathrm{Sml}_{2}$ (2.5 equiv), $n \mathrm{BuNH}_{2}$ (7.5 equiv) and $\mathrm{H}_{2} \mathrm{O}$ (12.5 equiv) were mixed with dithioacetal at $\mathrm{rt}$.

After 30 seconds of reaction, $\mathrm{Sml}_{2}$ associated to $\mathrm{H}_{2} \mathrm{O}$ and $n \mathrm{BuNH}_{2}$ promoted the intramolecular coupling reaction but also the hydrogenolysis of one of the carbon-sulfur bonds. By adding an excess of $\mathrm{Sml}_{2}$ and after a prolonged reaction time (between 1 to $2 \mathrm{~h}$ ), a second hydrogenolysis reaction 
occurred to provide the methyl compound (85\%). As it can be observed in this part dedicated to the desulfurization by other metals, protocols using $\mathrm{Na}$ and $\mathrm{Li}$ in liquid ammonia or amines are possible alternatives to the use of nickel reducing reagents for desulfurization reactions of dithioketals and dithioacetals but these methodologies probably cannot be applied to highly functionalized or fragile molecules.

\section{Other desulfurizing reagents}

\subsection{Metal hydrides}

\subsection{1. $\mathrm{Bu}_{3} \mathrm{SnH}$ with AIBN}

Gutierrez found in 1980, that in the presence of a radical initiator, $\mathrm{Bu}_{3} \mathrm{SnH}$ was an effective reducing agent for complete or partial desulfurization of dithioketals and dithioacetals. ${ }^{[32]}$ In the presence of 4 equiv of $\mathrm{Bu}_{3} \mathrm{SnH}$ and $\mathrm{AIBN}, 1,3$-dithiolanes were totally reduced to give their methylene derivatives in good yields (Scheme 14).

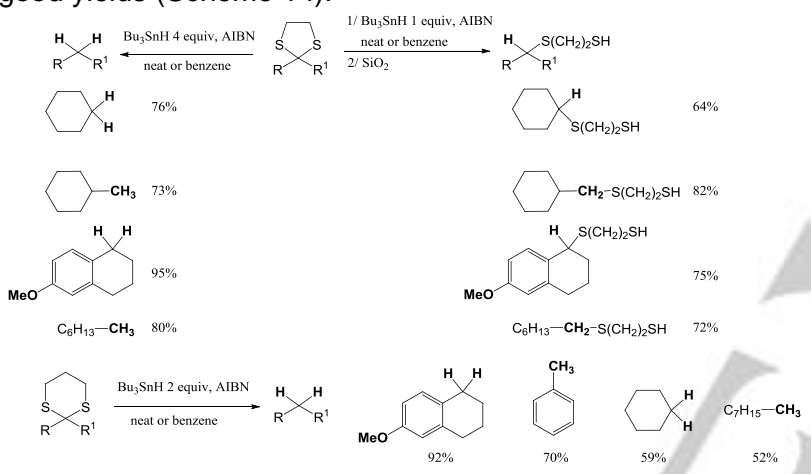

Scheme 14. Desulfurization of dithiolanes and dithianes with $\mathrm{Bu}_{3} \mathrm{SnH}$.

1,3-Dithiolanes were half desulfurized using 1 equiv of $\mathrm{Bu}_{3} \mathrm{SnH}$ to give quantitatively tri- $n$-butyltin sulfide products, which were destannylated on silica gel column. Gutierrez also demonstrated that 1,3-dithianes were easily desulfurized requiring only 2 equiv of $\mathrm{Bu}_{3} \mathrm{SnH}$ to give the totally reduced compounds. This reducing process was successfully used by Zhai during the total synthesis of aphanorphine, ${ }^{[33]}$ and also by Nagamitsu during the synthesis of Citridone $A^{[34]}$ (Scheme 15).

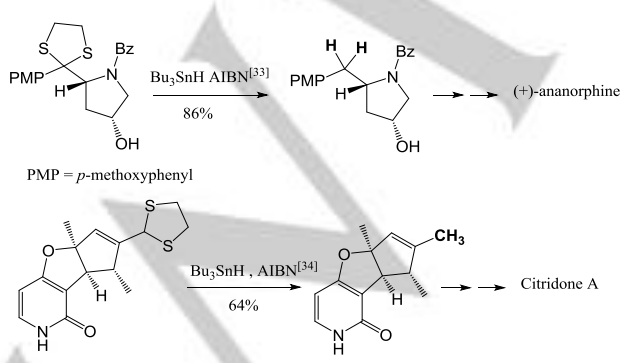

Scheme 15. Desulfurization of dithiolanes by $\mathrm{Bu}_{3} \mathrm{SnH}$ in total syntheses.
3.1.2. $B\left(C_{6} F_{5}\right)_{3}$ catalyzed desulfurization of thioketals in the presence of $\mathrm{Et}_{3} \mathrm{SiH}$

During a study dedicated to the reducing properties of hydrosilanes towards sulfides in the presence of a catalytic amount of $\mathrm{B}\left(\mathrm{C}_{6} \mathrm{~F}_{5}\right)_{3}$, Akiyama observed that this combination was able to totally desulfurize 2-naphtylthioketals in nearly quantitative yields (Scheme 16). ${ }^{[35]} \mathrm{Et}_{3} \mathrm{SiH}$ (3 to 6 equiv) which was preferable to $\mathrm{Ph}_{3} \mathrm{SiH}$ or $(\mathrm{EtO})_{3} \mathrm{SiH}$ reacted with thioketals and $2 \mathrm{~mol} \%$ of $\mathrm{B}\left(\mathrm{C}_{6} \mathrm{~F}_{5}\right)_{3}$ in $\mathrm{CHCl}_{3}$ to provide the totally reduced compounds.

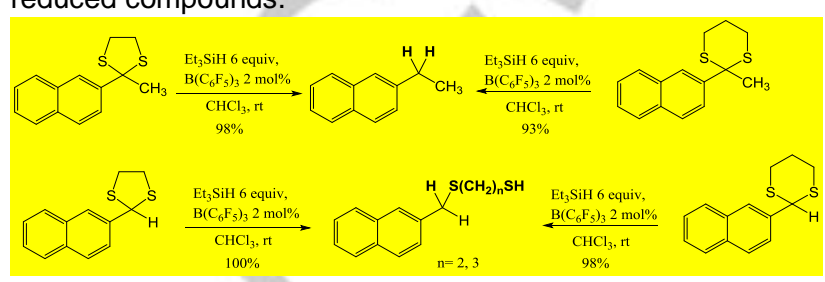

Scheme 16. Desulfurization and half desulfurization of thioketals using $\mathrm{Et}_{3} \mathrm{SiH}$ in the presence of $\mathrm{B}\left(\mathrm{C}_{6} \mathrm{~F}_{5}\right)_{3}$.

It is interesting to note that dithiolane and dithiane derived from 2-acetylnaphtalene were totally desulfurized to give their methylene derivatives, whereas dithiane and dithiolane prepared from 2-naphtalenecarbaldehyde were quantitatively half-desulfurized under the same experimental conditions, indicating that a methyl group close to the sulfur atom facilitated its coordination to the boron atom and then permitted the second reduction process.

\subsection{Metal-free desulfurizations}

\subsubsection{Hydrated hydrazine}

Giorgian and co-workers reported first in 1959 that hydrated hydrazine was able to desulfurize cyclic or acyclic thioketals in the presence of $\mathrm{KOH}^{[36]}$ They also showed that $\mathrm{KOH}$ was useful but not essential in this reducing process but lowered considerably the effective temperature of reactions. Some representative examples are reported in Scheme 17.
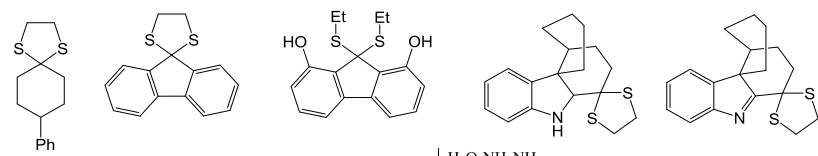

$$
60-95 \% \mid \begin{aligned}
& \mathrm{H}_{2} \mathrm{O}-\mathrm{NH}_{2} \mathrm{NH}_{2} \\
& \mathrm{KOH}, 90-135{ }^{\circ} \mathrm{C}
\end{aligned}
$$
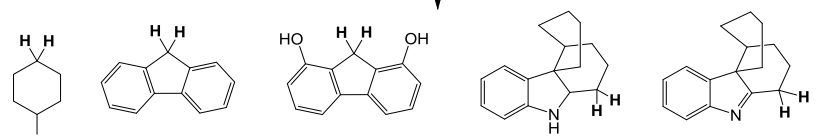

Scheme 17. Desulfurization of thioketals by $\mathrm{NH}_{2} \mathrm{NH}_{2}$ and $\mathrm{KOH}$.

Five years after the pioneer work of Giorgian, ${ }^{[36]}$ Corey described the total synthesis of Longifolene and studied the desulfurization of the dithiolane described in Scheme $18 .^{[37]}$ The authors reported that Raney-Ni was ineffective in achieving this transformation, on the contrary to hydrazine 
associated with $\mathrm{Na}$, which quantitatively desulfurized the dithiolane into the expected methylene compound.

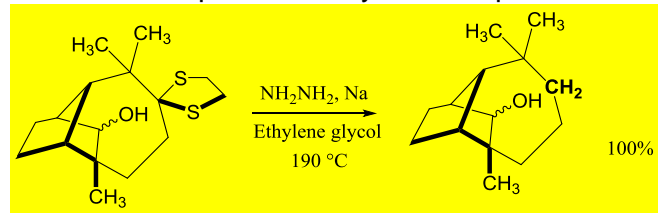

Scheme 18. Desulfurization of a dithioketal by $\mathrm{NH}_{2} \mathrm{NH}_{2}$ and $\mathrm{Na}$.

\subsection{2. $\mathrm{P}_{2} \mathrm{I}_{4}$ in $\mathrm{CH}_{2} \mathrm{Cl}_{2}$}

Shigemasa studied the desulfurization of dithiolanes by $\mathrm{P}_{2} \mathrm{I}_{4}$ and observed the fundamental role of solvents in these reactions. ${ }^{[38]}$ In $\mathrm{Ac}_{2} \mathrm{O}$, dithiolanes were deprotected by $\mathrm{P}_{2} \mathrm{I}_{4}$ (1 equiv) to provide their parent ketones, whereas in methylene chloride and water, methylene compounds were obtained as majors products (Scheme 19).

$$
\text { (1) }
$$

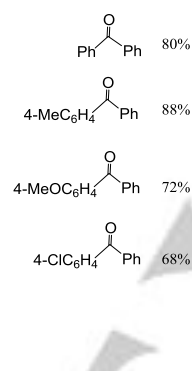

Scheme 19. Reduction of dithiolanes by $\mathrm{P}_{2} \mathrm{l}_{4}$ in $\mathrm{CH}_{2} \mathrm{Cl}_{2}$.

3.2.3. Photoreduction of dithianes and dithiolanes with tBuOK in DMSO

Recently, an Argentinian group reported an elegant desulfurization process of dithioketals using a photoinduced electron transfer from $t \mathrm{BuOK}$ in the presence of 1,4cyclohexadiene as hydrogen atom donor (Scheme 20). ${ }^{[39]}$

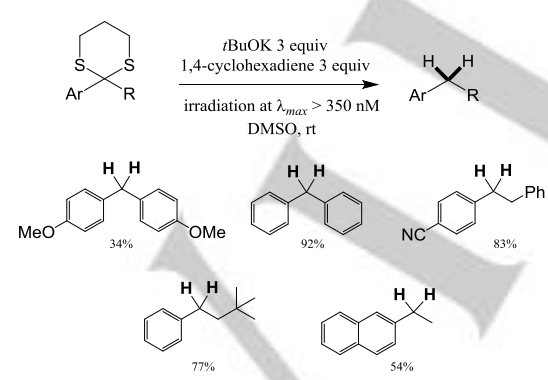

Scheme 20. Photoreduction of dithianes and dithiolanes with $t B u O K$ in DMSO.

The procedure seems to be compatible with both EDGs and EWGs on aromatic rings (e.g. CN, 83\%). The mechanism of the photochemical reduction of thioketals in DMSO was well investigated by the authors and others ${ }^{[40]}$ through calculations of quantum yield for products and for the initiation step.

\subsubsection{EtSNa in $\mathrm{MeOH}$}

The last example described in this review deals with the desulfurization of various 9,9-bis(ethylthio)fluorenes by EtSNa in $\mathrm{MeOH}$ (Scheme 21). ${ }^{[41]}$ Effects of neighboring ester groups (on $o, m$ and $p$-positions of the aromatic ring) on the reaction rate are discussed and compared. For the derivative having an ortho-ester function close to the sulfur atoms, steric hindrance and stabilization of the benzylic anion formed after the first C-S bond cleavage lowered the rate of the process.

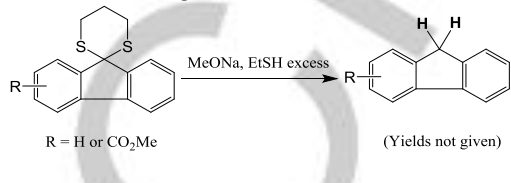

Scheme 21. Sodium ethanethiolate promoted the desulfurization of 9,9 bis(ethylthio)fluorenes.

\section{Conclusion}

The reducing desulfurization processes of thioketals into methylene or methyl derivatives were reviewed from the pioneer's works of Wolform and Karabinos until 2017. Raney$\mathrm{Ni}$ is the most used reagent to achieve this transformation and was used in many total syntheses, demonstrating its efficacy and a certain functional group tolerance. However, (I) the pyrophoric properties of Raney-Ni, (ii) the hazardous manipulations and difficulty to calculate the exact quantity of $\mathrm{Ni}$ in experiments, (iii) the presence or not of $\mathrm{H}_{2}$ in catalysts, (iv) the toxicity associated with the use of $\mathrm{Ni}$ and $\mathrm{Ni}$ derivatives ${ }^{[42]}$ and $(v)$ the use of $\mathrm{Ni}$ reducing reagent in more than stoichiometric amounts, limit the use from an industrial point of view and for large scale preparations. Other metals or metal salts can successfully replace $\mathrm{Ni}$ and $\mathrm{Ni}$ salts as $\mathrm{Na}$ and $\mathrm{Li}$ in $\mathrm{NH}_{3}$ or amines, Mo or $\mathrm{ZnCl}_{2}, \mathrm{CuCl}_{2}$ and $\mathrm{TiCl}_{4}$. However for these metals and metal salts, no complete studies were achieved to examine the scope and limitation of such methods. A similar comment can be applied to all other methodologies presented in this review, such as the use of metallic hydrides $\left(\mathrm{Bu}_{3} \mathrm{SnH}\right.$ and $\left.\mathrm{Et}_{3} \mathrm{SiH}\right)$ as well as metal-free processes and particularly the photochemical reduction of dithioketals, which is a promising method if applicable in highly functionalized molecules. There is an urgent need to find a soft metal-free methodology to desulfurize dithioketals, which is easy to handle, tolerant towards functional groups and provides the expected reduced products in high yields.

\section{Acknowledgments}

Authors gratefully acknowledge support of this project by CNRS, Univ. Paris-Saclay, and by La Ligue Nationale Contre le Cancer through an Equipe Labellisée 2014 grant. Guangkuan Zhao and Ling-Zhi Yuan thank the CSC (Chinese Scholarship Council) for a Ph.D. funding. Our laboratory (BioCIS UMR 8076) is a member of the laboratory of excellence LERMIT supported by a grant from ANR (ANR-10LABX-33) 


\section{Conflict of Interest}

The authors declare no conflict of interest.

Keywords: desulfurization . Ni derivatives - reduction. thioacetal $\cdot$ thioketal

[1] a) J. Bougault, E. Cattelain, P. Chabrier, Bull. Chem. Soc. Chim. 1938, 5, 1699-1712; b) L. Wolfrom, J. V. Karabinos, J. Am. Chem. Soc. 1944, 66, 909-911.

[2] G. R. Pettit, E. E. van Tamelen, Org. React. 1962, 12, 356-529.

[3] Inexpensive Raney-Ni is commercially available.

[4] a) M. Raney, U.S. Patent 1,563,587 (Dec. 1, 1925); Chem. Abstracts 1926, 20, 515; b) M. Raney, U.S. Patent 1,628,190 (May 10, 1927); Chem. Abstracts 1927, 21, 2116; c) M. Raney, U.S. Patent 1,915,473 (Jun. 27, 1933); Chem. Abstracts 1933, 27, 4361.

[5] a) R. Mozingo, D. E. Wolf, S. A. Harris, K. Folkers, J. Am. Chem. Soc. 1943, 65, 1013-1016; b) R. Mozingo, Org. Syntheses Collective Vol. 3 , 181 (1955); c) P. Ruggli, E. Preiswerk, Helv. Chim. Acta 1939, 22, 478495.

[6] E. Eich, H. Pertz, M. Kaloga, J. Schulz, M. R. Fesen, A. Mazumder, Y. Pommier, J. Med. Chem. 1996, 39, 86-95.

[7] Y. Unoh, K. Hirano, T. Satoh, M. Miura, Org. Lett. 2015, 17, 704-707.

[8] N. Chandrasoma, N. Brown, A. Brassfield, A. Nerurkar, S. Suarez, K. R. Buszek, Tetrahedron Lett. 2013, 54, 913-917.

[9] A. L. Hurski, M. V. Barysevich, T. S. Dalidovich, M. V. Irkryk, N. U. Kolasava, V. N. Zhabinskii, V. A. Khripach, Chem. Eur. J. 2016, 22, $14171-14174$

[10] For an excellent review on reductive desulfurization of complex molecules by Raney-Ni please see: a) J. Rentner, M. Kljajic, L. Offner, R. Breinbauer, Tetrahedron 2014, 70, 8983-9027; b) S. H. Yu, W. Zhu, D. W. Ma, J. Org. Chem. 2005, 70, 7364-7370; c) M. De Paolis, H. Rosso, M. Henrot, C. Prandi, F. d'Herouville, J. Maddaluno, Chem. Eur. J. 2010 16, 11229-11232; d) H. Suginome, S. Yamada, J. B. Wang, J. Org. Chem. 1990, 55, 2170-2176; e) J. Shiina, M. Oikawa, K. Nakamura, R. Obata, S. Nishiyama, Eur. J. Org. Chem. 2007, 5190-5197; f) E. Eich, H. Pertz, M. Kaloga, J. Schulz, M. R. Fesen, A. Mazumder, Y. Pommier, J. Med. Chem. 1996, 39, 86-95. g) N. Rehnberg, G. Magnusson, J. Org. Chem. 1990, 55, 4340-4349; h) C. Liu, Q. Yin, L. X. Dai, S. L. You, Chem. Commun. 2015, 51, 5971-5974; i) J. M. Ren, P. Zhao, X. Xiao, T. Q. Chen, B. B. Zeng, Synthesis 2016, 48, 4161-4166; j) S. A. Snyder, E. J. Corey, J. Am. Chem. Soc. 2006, 128, 740-742; k) Y. Q. Feng, M. M. Majireck, S. M. Weinreb, J. Org. Chem. 2014, 79, 7-24; I) A. A. Momin, T. D. Urmode, S. M. Bhosale, R. S. Kusurkar, Synth. Commun. 2016, 46, 1292-1298.

[11] H. Hauptmann, W. F. Walter, Chem. Rev.1962, 62, 347-404

[12] a) L. Mordenti, J. J. Brunet, P. Caubère, J. Org. Chem. 1979, 44, 22032205; b) J. J. Brunet, P. Gallois, P. Caubère, J. Org. Chem. 1980, 45 , 1937-1945; c) P. Gallois, J. J. Brunet, P. Caubère, J. Org. Chem. 1980 45, 1946-1950; d) R. Vanderesse, J. J. Brunet, P. Caubère, J. Org. Chem. 1981, 46, 1270-1277; e) J. J. Brunet, D. Besozzi, A. Courtois, P. Caubère, J. Am. Chem. Soc. 1982, 104, 7130-7135; f) Y. Fort, R. Vanderesse, P. Caubère, Tetrahedron Lett. 1985, 26, 3111-3114; g) Y. Fort, R. Vanderesse, P. Caubère, Tetrahedron Lett. 1986, 27, 5487-5490; h) G. Feghouli, R. Vanderesse, Y. Fort, P. Caubère, Tetrahedron Lett. 1988, 29, 1383-1384.

[13] a) R. Vanderesse, J. J. Brunet, P. Caubère, J. Organomet. Chem. 1984 264, 263-271; b) R. Vanderesse, Y. Fort, S. Becker, P. Caubère, Tetrahedron Lett. 1986, 27, 3517-3520; c) R. Vanderesse, M. Lourak, Y. Fort, P. Caubère, Tetrahedron Lett. 1986, 27, 5483-5486; d) M. Lourak, R. Vanderesse, Y. Fort, P. Caubère, Tetrahedron Lett. 1988, 29, 545548; e) M. Lourak, R. Vanderesse, Y. Fort, P. Caubère, J. Org. Chem. 1989, 54, 4840-4844; f) M. Lourak, R. Vanderesse, Y. Fort, P. Caubère, J. Org. Chem. 1989, 54, 4844-4848.

[14] a) S. Becker, Y. Fort, R. Vanderesse, P. Caubère, Tetrahedron Lett. 1988, 29, 2963-2966; b) S. Becker, Y. Fort, P. Caubère, J. Org. Chem. 1990, 55, 6194-6198; c) C. Kuehm-Caubère, A. Guilmart, S. AdachBecker, Y. Fort, P. Caubère, Tetrahedron Lett. 1998, 39, 8987-8990; d) half desulfurization of thioketals was also achieved using $\mathrm{Ca}$ in ammonia see: B. C. Newman, E. L. Eliel, J. Org. Chem. 1970, 35, 3641-3646.

[15] P. Caubère, Angew. Chem. Int. Ed. Engl. 1983, 22, 599-613.

[16] R. R. Boar, D. W. Hawkins, J. F. McGhie, D. H. R. Barton, J. Chem. Soc. Perkin Trans. 1 1973, 654-657.

[17]a) J. M. Khurana, D. Magoo, Synth. Commun. 2010, 40, 2908-2913; b) M. Amat, M. Pérez, N. Llor, C. Escolano, F. J. Luque, E. Molins, J. Bosch, J. Org. Chem. 2004, 69, 8681-8693.

[18] W. E. Truce, F. E. Roberts, J. Org. Chem. 1963, 28, 961-964.

[19] K. M. Ho, C. H. Lam, T. Y. Luh, J. Org. Chem. 1989, 54, 4474-4476.

[20] M. C. Chan, K. M. Cheng, K. M. Ho, C. T. Ng, T. M. Yam, B. S. L. Wang, T. Y. Luh, J. Org. Chem. 1988, 53, 4466-4471.

[21] a) W. K. Schroop, J. Inorg. Nucl. Chem. 1962, 24, 1688-1690. b) P. C. Ellgen, C. D. Gregory, Inorg. Chem. 1971, 10, 980-984.

[22] N. F. Ho,T. C. W. Mak,T. Y. Luh, Organomet. Chem. 1986, 317, C28C30.

[23] R. E. Ireland, T. I. Wrigley, W. G. Young, J. Am. Chem. Soc. 1958, 80, 4604-4606.

[24] I. Degani, R. Fochi, J. Chem. Soc. Perkin Trans. 11978, 1133-1136.

[25] J. S. Prasad, D. L. J. Clive, G. V. J. da Silva, J. Org. Chem. 1986, 51, 2717-2721.

[26] J. A. M. Peters, T. A. P. Posthumus, N. P. van Vliet, F. J. Zeelen, J. Org. Chem. 1980, 45, 2208-2214.

[27] a) N. S. Crossley, H. B. Henbest, J. Chem. Soc. 1960, 4413-441; b) S. Kuwahara, Shibata, A. Hiramatsu, Liebigs Ann. Chem. 1992, 993-995.

[28] a) T. Mukaiyama, K. Narasaka, K. Maekawa, M. Furusato, Bull. Chem. Soc. Jpn 1971, 44, 2285; b) T. Mukaiyama, M. Hayashi, K. Narasaka, Chem. Lett. 1973, 291-293.

[29] H. Alper, C. Blais, Fuel, 1980, 59, 670.

[30] T. Y. Luh, C. S. Wong, J. Org. Chem. 1985, 50, 5413-5415.

[31] A. Dahlén,A. Petersson,G. Hilmersson,Org. Biomol. Chem. 2003, 1, 2423-2426.

[32] a) C. G. Gutierrez, R. A. Stringham, T. Nitasaka, K. G. Glasscock, J. Org. Chem.1980, 45, 3393-3395; b) K. Schmidt,S. O'Neal,T. C. Chan, C. P. Alexis,J. M. Uribe, K. Lossener, C. G. Gutierrez, Tetrahedron Lett. 1989, 30, 7301-7304; c) C. G. Guterriez, C. P. Alexis, J. M. Uribe, J. Chem. Soc., Chem. Commun. 1984, 124-125.

[33] Z. Ma, H. Hu, W. Xiong, H. Zhai, Tetrahedron 2007, 63, 7523-7531.

[34] T. Miyagawa, K. Nagai, A. Yamada, Y. Sugihara, T. Fukuda, R. Uchida, H. Tomoda, S. Omura, T. Nagamitsu, Org. Lett. 2011, 13, 1158-1161.

[35] K. Saito, K. Kondo, T. Akiyama, Org. Lett. 2015, 17, 3366-3369.

[36] V. Georgian, R. Harrisson, N. Gubisch, J. Am. Chem. Soc. 1959, 81, 5834-5835.

[37] E. J. Corey, M. Ohno, R. B. Mitra, P. A. Vatakencherry, J. Am. Chem. Soc. 1964, 86, 478-485.

[38] Y. Shigemasa, M. Ogawa, H. Sashiwa, H. Saimoto, Tetrahedron Lett. 1989, 30, 1277-1278.

[39] G. Oksdath-Mansilla, J. Argüello, A. B. Pénénory, Tetrahedron Lett. 2013, 54, 1515-1518.

[40] G. Goulthard, K. J. Emery, E. Doni, F. Cumine, G. Nocera, M. P. John, L. E. A. Berlouis, T. McGuire, T. Tuttle, J. A. Murphy, J. Am. Chem. Soc. 2016, 138, 7402-7410.

[41] W. Nakanishi, H. Nakanishi, Y. Yanagawa, Y. Ikeda, M. Oki, Chem. Lett. 1983, 105-108.

[42] For a review on toxicity and carginogenicity of nickels compounds see: $T$. P. Coogan, D. M. Latta, E. T. Snow, M. Costa, Crit. Rev. Toxicol. 1989, 19, 341-384. 


\section{Entry for the Table of Contents}

Insert graphic for Table of Contents here. ((Please ensure your graphic is in one of following formats))

$\mathrm{R}=\mathrm{Ar}$, alk

$\mathrm{R}^{1}=\mathrm{Ar}$, alk, $\mathrm{H}$

$\mathrm{R}^{2}=\mathrm{Ar}$, alk

$\mathrm{R}_{2} \stackrel{\mathrm{R}_{2}}{ }$

$\mathrm{s}_{\mathrm{R}}^{\mathrm{s}} \mathrm{s}_{\mathrm{R}^{1}}$

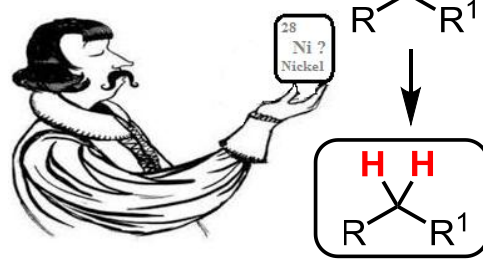

This review reports the total desulfurization of thioacetals and thioketals, leading to methyl and methylene derivatives, through metals, metal-hydrides and metal-free methodologies used between 1944 until 2017. Applications to functionalized molecules in a variety of complex or total syntheses is also presented. 